\title{
The Relationship Between Coronary Collateral Circulation and Visceral Fat
}

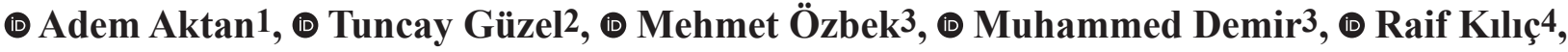 \\ (1) Bayram Arslan5, (1) Burhan Aslan2
}

\author{
${ }^{1}$ Mardin State Hospital, Clinic of Cardiology, Mardin, Turkey \\ ${ }^{2}$ University of Health Sciences Turkey, Gazi Yaşargil Training and Research Hospital, Department of Cardiology, Diyarbakır, Turkey \\ 3Dicle University Faculty of Medicine, Department of Cardiology, Diyarbakır, Turkey \\ ${ }^{4}$ Tatvan Can State Hospital, Clinic of Cardiology, Bitlis, Turkey \\ 5Ergani State Hospital, Clinic of Cardiology, Diyarbakır, Turkey
}

\begin{abstract}
Objectives: Collateral circulation is assumed to prevent myocardial ischemia in healthy subjects and in patients with coronary artery disease. Visceral adipose tissue is an active component of total body fat, which holds some biochemical characteristics that have impact on several normal and pathological processes in the human body. In this study, we investigated the relationship between visceral fat ratio and coronary collateral circulation (CCC).

Materials and Methods: Totally 148 patients with stable angina pectoris were recruited to the study and all patients' heights and weights were recorded after the coronary angiography. The study subjects were divided into two groups as those between 1 and 9 , and those $>10$ by classifying their visceral fat ratio with bioelectrical impedance analysis method. Patients were classified as poor CCC group (grade 0 and 1) and good CCC group (grade 2 and 3) based on the Rentrop's classification of CCC.

Results: In the analysis in accordance with collateral classification, visceral fat percentage (13.7 \pm 4.7 versus 10.1 \pm 4.0 , $\mathrm{p}=0.01)$ and body mass index $(28.2 \pm 2.4$ versus $27.3 \pm 2.3, \mathrm{p}=0.040)$ were found significantly higher in the poor collateral group. Diabetes mellitus was significantly higher in patient with high visceral fat ratio. In multivariate logistic regression analysis for collateral growth, visceral fat percentage [odds ratio (OR): $0.740, \% 95$ confidence interval (CI): 0.602 -
\end{abstract}

Address for Correspondence: Adem Aktan, Mardin State Hospital, Clinic of Cardiology, Mardin, Turkey

e-mail: dradem21@hotmail.com ORCID: orcid.org/0000-0003-0505-9784

Received: 22.01.2021 Accepted: 31.01.2021

Cite this article as: Aktan A, Güzel T, Özbek M, Demir M, Kılıç R, Arslan B, Aslan B. The Relationship Between Coronary

Collateral Circulation and Visceral Fat. EJCM 2021;9(1):27-38.

DOI: 10.32596/ejcm.galenos.2021-01-05

${ }^{\circ}$ Copyright 2021 by Heart and Health Foundation of Turkey (TÜSAV) / E Journal of Cardiovascular Medicine published by Galenos Publishing House. 


\begin{abstract}
$0.909, \mathrm{p}=0.040]$ and coronary stenosis percentage (OR: $1.220, \% 95 \mathrm{CI}: 1.070-1.390, \mathrm{p}=0.003$ ) were found meaningful, independent from the other factors. In ROC analysis, increase in visceral fat level decreased collateral growth with $72.7 \%$ sensitivity and $58.5 \%$ specificity.
\end{abstract}

Conclusion: The increase in visceral fat seems an independent factor for poor collateral development.

Keywords: Coronary artery disease, collateral vessel, visceral fat, coronary artery disease risk factor

\section{Introduction}

Coronary artery disease (CAD) is a progressive, systemic and inflammatory disease with atherosclerosis in its etiology ${ }^{(1)}$. Coronary collateral circulation (CCC) is defined as vascular structures those present nonfunctional in the normal heart, becomes activated upon a serious stenosis or complete obstruction, disrupts blood circulation as an adapting response between the sections of the same coronary artery or different coronary arteries in order to provide blood flow into the ischemic myocardial $\operatorname{area}^{(2)}$. Collateral circulation is quite crucial since it is a potential alternative source upon any insufficiency in coronary arteries for providing blood circulation. Anti-ischemic effects, reducing myocardial infarction frequency, limiting infarct area, preventing the formation of aneurysms, maintaining ventricular functions, antiarrhythmic effects, and decreasing coronary mortality are the benefits of $\mathrm{CCC}^{(3-6)}$. It is a fact that the status of the collaterals is different even between individuals even with the same level of artery disease ${ }^{(7)}$. Visceral fat is a unique part of the total body fat and possesses several biochemical functions. Visceral fat is associated with a constellation of various metabolic abnormalities, including insulin resistance, hyperinsulinemia, type 2 diabetes, dyslipidemia, inflammation, and altered cytokine profile. Such metabolic abnormalities may have an effect on the endothelial tissue which is in the cornerstone point of development of new vessels in injured or ischemic tissues.

In our study, we have tried to show the relationship between visceral fat percentage, which is one of the factors considered to be efficient in coronary collateral vessel development, and CCC development.

\section{Materials and Methods}

\section{Study Population}

Our patients were selected from the cases who applied to our center due to chest pain and were hospitalized in our clinic after receiving coronary angiography indication with stable angina pectoris diagnosis after routine examinations. All patients were informed preceding the study.

Coronary angiography images, which were performed in our cardiology angiography laboratory, were scanned, and post-procedure hospital records were examined for patients with at least $90 \%$ and above critical stenosis in at least one of their coronary arteries. Baseline demographic data and laboratory results were obtained from the cases and hospital database system. Echocardiographic examination and electrocardiography were performed in all patients during the hospital stay. Left ventricular ejection fraction was measured using the Modified Simpson Method.

Among 200 patients who were eligible for the study criteria, patients with acute coronary syndrome requiring intervention in the first 72 hours, cancer, hematological disease, hypothyroidism, serious valvular heart disease, decompensated heart failure, severe liver disease, autoimmune disease, chronic kidney disease, inflammatory and infectious disease, corticosteroids or cytotoxic drug use, bedbound patients with a history of bleeding diathesis, patients weighing above $150 \mathrm{~kg}$ or 
below $40 \mathrm{~kg}$, patients whose height was above $180 \mathrm{~cm}$ or below $140 \mathrm{~cm}$, and patients under 18 or over 80 years old were excluded from the study. Our study included 148 patients who were eligible according to inclusion criteria.

\section{Coronary Angiography}

By using right and left femoral approach, selective coronary angiography was performed to patients with the Judkins method by using $6 \mathrm{~F}$ or $7 \mathrm{~F}$ catheters. Coronary angiography images were evaluated by two experienced cardiologists who had no knowledge on the clinical characteristics and laboratory data of patients. The levels of stenosis in coronary arteries were determined depending on the projection with the highest stenosis. Collateral development was evaluated according to the Rentrop classification. The grades of the evaluation according to the Rentrop classification were as follows: Rentrop grade 0 : No collateral fill, Rentrop grade 1: very weak collateral flow, but no filling in epicardial arteries, Rentrop grade 2: Partial filling, presence of contrast material on epicardial arteries but no complete filling, Rentrop grade 3: Complete perfusion, contrast material determined to fill epicardial vessels completely. Rentrop Grades 0 and 1 were evaluated as poorly developed collateral circulation, while Rentrop grades 2 and 3 were evaluated as welldeveloped collateral circulation ${ }^{(8)}$.

\section{Visceral Fat Percentage, Body Mass Index and Waist Circumference Measurement}

Body weight in kilograms and height in centimeters were measured and recorded before the discharge of patients. Body mass index (BMI) was obtained by dividing body weight in $\mathrm{kg}$ to the square of the height in meters. Body fat tissue percentage (\%) and visceral fat percentage (\%) were measured with the Omron HBF-500 Digital Body Analysis Scale that worked with Bioelectrical Impedance Analysis method ${ }^{(9)}$.

\section{Statistical Analysis}

All analyses were performed with SPSS version 18.0
(SPSS Inc., Chicago, Illinois, USA). The KolmogorovSmirnov and Shapiro-Wilk tests were used to determine whether the distribution of continuous variables fit in normal. Descriptive statistics were expressed as mean \pm standard deviation for continuous variables, and case number and (\%) for nominal variables. The continuous variables showing normal distribution were compared with the Student's t-test, while continuous variables with no normal distribution were compared by using the MannWhitney U test. The chi-square test or Fischer's Exact test were used in the comparison of categorical variables. Statistical significance was assumed for $p$-value $<0.05$. The Pearson correlation test was used in the evaluation of the relationship between parameters with normal distribution, while the Spearman's rho correlation test was used to examine the relationship between parameters that did not show normal distribution. Multivariate logistic regression analysis was used for evaluating independent markers on collateral use during analysis. Receiver operating characteristic (ROC) analysis was performed in order to determine the sensitivity and specificity of estimating the negative effect of visceral fat tissue, BMI and increase in waist circumference on coronary collateral development.

\section{Results}

A total of 148 patients were included in our study, consisting of 64 females (43.2\%) and 84 males (56.8\%) aged between 41 and 80 years with the mean age of $62 \pm 8.8$ years.

From an angiographic aspect, 66 patients were classified in the good collateral group, and 82 patients were in the poor collateral group. Patients with good collaterals and poor collaterals were compared according to their demographic and clinical characteristics (Table 1).

Patients who were included in the study were separated in two groups according to visceral fat percentage. Those with values between $1 \%$ and $9 \%$ were placed in group 1 while those with values above $10 \%$ were placed in group 2. Ninety-three of those had high visceral fat percentage 
and remaining 55 patients were determined to have low visceral fat percentage.

Visceral fat percentage level of patients in the poor collateral group varied between $5 \%$ and $24 \%$, and the mean visceral fat percentage was determined as $13.7 \% \pm 4.7 \%$. Meanwhile, visceral fat percentage level of patients in the good collateral group varied between $6 \%$ and $20 \%$, and the mean visceral fat percentage was determined as $10.1 \pm 4.0 \%$. This difference was determined to be statistically significant $(\mathrm{p}=0.011)$.

Laboratory results of the patients are shown in Table 2. The comparison of coronary angiographic and echocardiographic characteristics of the groups is presented in Table 3. Upon analyzing the relationship between the $\mathrm{CCC}$ and visceral fat percentage, linkage analyses are shown in Figure 1 according to the distinction of good and poor collateral and Rentrop classification.

A weak negative correlation was determined upon performing correlation analysis between collateral level and visceral fat percentage, and despite being modest, it was

Table 1. Demographic and clinical characteristics of patients found to be statistically significant $(\mathrm{r}=-0.415, \mathrm{p}<0.001)$. A very weak correlation was found upon performing correlation analysis between collateral development and BMI $(r=-0.211, p=0.010)$ and waist circumference $(\mathrm{r}=-0.203, \mathrm{p}=0.013)$, and it was also determined to be statistically significant. There was a very weak correlation between collateral development and diabetes mellitus (DM) and it was found to be statistically significant $(\mathrm{r}=0.184, \mathrm{p}=0.025)$. There was also a moderately positive but statistically significant correlation between stenosis percentage and collateral development $(r=0.548, \mathrm{p}<0.001)$.

The patients included in the study were divided into two groups: those with visceral fat ratio between 1 and 9 and those above 10. In 93 of these, visceral fat ratio was above 10 (high), and in the remaining 55 patients, it was observed between 1 and 9 (low). 52.7\% of patients with low visceral fat ratio were male, and $59.1 \%$ of those with high ratio were male. However, no statistically significant difference was found $(\mathrm{p}=0.447)$. The mean age of the patients with low visceral fat ratio was $63.5 \pm 9.6$ years,

\section{Demographic and clinical characteristics}

Age, years

Gender, (\%)

Male

BMI, $\left(\mathrm{kg} / \mathrm{m}^{2}\right)$

Waist circumference, $(\mathrm{cm})$

Visceral fat

Between 1-9

$\mathrm{HT}, \mathrm{s}(\%)$

DM, s (\%)

Dyslipidemia, s (\%)

Smoking, s (\%)

Family history, s (\%)

Antiplatelet agents, s (\%)

Beta blockers, s (\%)

ACE inh/ARB, s (\%)

Statin, s (\%)

BMI: Body mass index, HT: Hypertension, DM: Diabetes mellitus, ACE inh: Angiotensin converting enzyme inhibitors, ARB: Angiotensin receptor blockers, n: Number

Important p-values shown as bold

\begin{tabular}{|c|c|c|c|c|c|}
\hline \multicolumn{3}{|c|}{ Demographic and clinical characteristics } & $\begin{array}{l}\text { Poor collateral } \\
(n=82)\end{array}$ & $\begin{array}{l}\text { Good collateral } \\
(n=66)\end{array}$ & $\mathbf{p}$ \\
\hline Age, years & & & $61.2 \pm 9.3$ & $63.0 \pm 8.2$ & 0.233 \\
\hline \multirow{2}{*}{\multicolumn{2}{|c|}{ Gender, (\%) }} & Male & $43(52.4 \%)$ & $41(62.1 \%)$ & \multirow{2}{*}{0.237} \\
\hline & & Female & $39(47.6 \%)$ & $25(37.9 \%)$ & \\
\hline \multicolumn{3}{|l|}{ BMI, $\left(\mathbf{k g} / \mathrm{m}^{2}\right)$} & $28.2 \pm 2.4$ & $27.3 \pm 2.3$ & 0.040 \\
\hline Visceral fat & 10 and above & & $59(72.0 \%)$ & $34(51.5 \%)$ & 0.011 \\
\hline \multicolumn{3}{|l|}{ HT, s (\%) } & $53(64.6 \%)$ & $39(59.1 \%)$ & 0.489 \\
\hline \multicolumn{3}{|l|}{ DM, s (\%) } & $33(40.2 \%)$ & $18(27.3 \%)$ & 0.099 \\
\hline \multicolumn{3}{|c|}{ Dyslipidemia, s (\%) } & $62(75.6 \%)$ & $47(71.2 \%)$ & 0.546 \\
\hline \multicolumn{3}{|c|}{ Beta blockers, s (\%) } & $49(59.8 \%)$ & $37(56.1 \%)$ & 0.651 \\
\hline \multicolumn{3}{|c|}{ ACE inh/ARB, s (\%) } & $43(52.4 \%)$ & $28(42.4 \%)$ & 0.225 \\
\hline \multicolumn{3}{|l|}{ Statin, s (\%) } & $30(36.6 \%)$ & 27 (40.9\%) & 0.591 \\
\hline
\end{tabular}

Poor collateral $(n=82)$

$43(52.4 \%)$

Female

10 and above

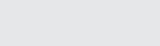



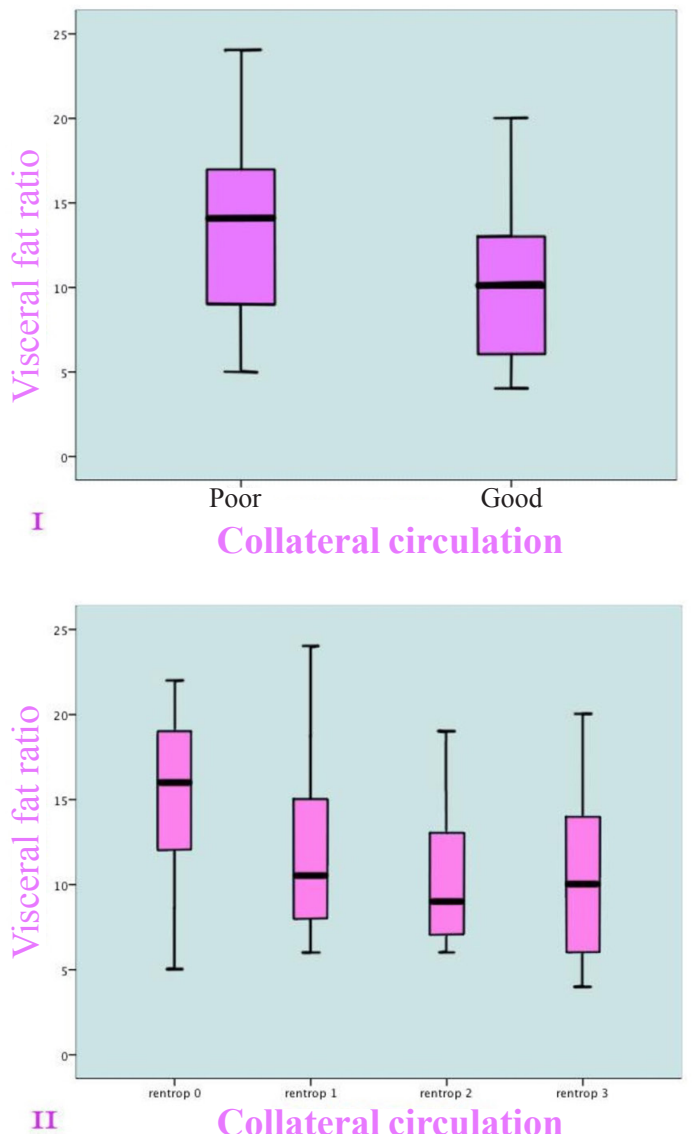

Figure 1. Linkage analyses between coronary collateral circulation and visceral fat percentage: (I) According to the distinction of good and poor collateral, (II) According to Rentrop classification

Table 2. Laboratory results of study groups

\begin{tabular}{|c|c|c|c|}
\hline Laboratory results & $\begin{array}{l}\text { Poor collateral } \\
(n=82)\end{array}$ & $\begin{array}{l}\text { Good collateral } \\
(n=66)\end{array}$ & $\mathbf{p}$ \\
\hline WBC, $\left(x 10^{3} \mu \mathrm{L}\right)$ & $8.6 \pm 1.4$ & $8.2 \pm 1.9$ & 0.139 \\
\hline Neutrophil & $5.3 \pm 1.5$ & $4.7 \pm 1.6$ & 0.016 \\
\hline Lymphocyte & $2.2 \pm 0.69$ & $2.0 \pm 0.71$ & 0.044 \\
\hline Hemoglobin, g/dL & $13.6 \pm 1.7$ & $13.8 \pm 1.7$ & 0.465 \\
\hline MCV & $84.2 \pm 4.4$ & $85.4 \pm 4.7$ & 0.110 \\
\hline Platelet (x10 $\left.0^{3} \mu \mathrm{L}\right)$ & $280 \pm 85.0$ & $262 \pm 61.5$ & 0.147 \\
\hline Glucose, mg/dL & $153 \pm 55.5$ & $142 \pm 51.6$ & 0.215 \\
\hline Creatinine, mg/dL & $0.89 \pm 0.2$ & $0.90 \pm 0.19$ & 0.798 \\
\hline LDL, mg/dL & $112.3 \pm 40.7$ & $109.8 \pm 35.0$ & 0.693 \\
\hline $\mathrm{HDL}, \mathrm{mg} / \mathrm{dL}$ & $40.5 \pm 7.2$ & $40.4 \pm 8.8$ & 0.989 \\
\hline Triglycerides, mg/dL & $200 \pm 95.7$ & $175 \pm 80.6$ & 0.091 \\
\hline
\end{tabular}

and the ratio was $61.1 \pm 8.2$ in those with high ratio. There was no statistically significant relationship $(p=0.108)$. We compared visceral fat ratio with each of the cardiovascular risk factors. Those with high visceral fat were found to be higher than those with low visceral fat; DM (40 vs 11 patients, $\mathrm{p}=0.004$ ), hypertension (HT) (61 vs 33 patients, $\mathrm{p}=0.495$ ), dyslipidemia (71 vs 38 patients, $\mathrm{p}=0.333$ ), smoking (35 vs 19 patient, $\mathrm{p}=0.706$ ), family history of CAD (31 vs 14 patients, $p=0.314$ ). However, except DM, there was no statistically significant difference (Table 4).

Visceral fat ratio was found to be significantly higher in those with higher BMI and waist circumference $(\mathrm{p}<0.001)$. The mean BMI was found to be $26.0 \pm 1.7$ in those with low visceral fat, while it was found to be $28.8 \pm 2.2$ in those with high visceral fat. Waist circumference was $92.6 \pm 7.6$ in those with low visceral fat, while it was $100 \pm 7.7$ in those with high visceral fat. In addition, In laboratory parameters compared with low and high visceral fats, respectively, triglyceride $(170 \pm 82.9$ vs $201 \pm 92.3, \mathrm{p}=0.042)$ and cholesterol $(179 \pm 42.6$ vs $195 \pm 47.9, \mathrm{p}=0.037$, respectively) were higher. This was statistically significant (Table 4).

Very weak negative and positive correlations were determined in the correlation analysis of other parameters that might affect collateral development, and no statistically significant difference was determined between the groups Important p-values shown as bold 
(Table 5). In the correlation between and cardiovascular risk factors, a statistically significant positive correlation was determined between visceral fat percentage and DM $(\mathrm{r}=0.314, \mathrm{p}<0.001)$.

A high positive correlation with BMI $(r=0.704$, $\mathrm{p}<0.001)$ and a moderate positive correlation with waist circumference $(\mathrm{r}=0.592, \mathrm{p}<0.001)$ were determined upon performing correlation between BMI and waist circumference and visceral fat percentage, and they were determined to be statistically significant.

In the correlation between triglyceride and cholesterol levels and visceral fat percentage, a statistically significant

Table 3. Coronary angiographic and echocardiographic characteristics of groups

\begin{tabular}{|l|l|l|l|}
\hline & & $\begin{array}{l}\text { Poor collateral } \\
(\mathbf{n = 8 2 )}\end{array}$ & Good collateral (n=66) \\
\hline & LAD & $38(46.3 \%)$ & $29(43.9 \%)$ \\
\hline Critical coronary vessel & Cx & $21(25.6 \%)$ & $12(18.5 \%)$ \\
\hline & RCA & $23(28.0 \%)$ & $25(37.9 \%)$ \\
\hline & Rentrop 0 & $46(56.1 \%)$ & 0 \\
\hline Rentrop collateral grade & Rentrop 1 & $36(43.9 \%)$ & 0 \\
\hline Stenosis percentage, (\%) & Rentrop 2 & 0 & $25(37.9 \%)$ \\
\hline \multirow{2}{*}{ Lesion location } & Rentrop 3 & 0 & $41(62.1 \%)$ \\
\hline LVEF, (\%) & Proximal & $93.5 \pm 4.4$ & $97.1 \pm 4.3$ \\
\hline LAD: Left anterior descending artery, Cx: Circumflex, RCA: Right coronary artery, LVEF: Left ventricular ejection fraction, $n$ : Number & $35(53 \%)$ \\
\hline
\end{tabular}

Table 4. The comparison of visceral fat percentage and clinical and demographic characteristics

\section{Visceral fat}

Age, years

Gender, (\%)

\section{Male}

Female

BMI, $\left(\mathrm{kg} / \mathrm{m}^{2}\right)$

Waist circumference, (cm)

HT, (\%)

DM, (\%)

Dyslipidemia, (\%)

Smoking, (\%)

History of CAD, (\%)

Family history, (\%)

Triglycerides, $\mathrm{mg} / \mathrm{dL}$

Cholesterol, $\mathrm{mg} / \mathrm{dL}$

HDL, $\mathrm{mg} / \mathrm{dL}$

LDL, $\mathrm{mg} / \mathrm{dL}$

\begin{tabular}{l}
$\begin{array}{l}\text { Between } 1 \text { a } \\
(n=55)\end{array}$ \\
$63.5 \pm 9.6$ \\
$29(52.7 \%)$ \\
$26(47.3 \%)$ \\
$26.0 \pm 1,7$ \\
$92.6 \pm 7.6$ \\
\hline $33(60 \%)$ \\
$11(20 \%)$ \\
\hline $38(69.1 \%)$ \\
\hline $19(34.5 \%)$ \\
\hline $31(56.4 \%)$ \\
\hline $14(25.5 \%)$ \\
\hline $170 \pm 82.9$ \\
\hline $179 \pm 42.6$ \\
\hline $41.7 \pm 9.5$ \\
\hline $103.8 \pm 34.4$
\end{tabular}

Between 1 and 9

$63.5 \pm 9.6$

$26(47.3 \%)$

$26.0 \pm 1,7$

$92.6 \pm 7.6$

$11(20 \%)$

$38(69.1 \%)$

$19(34.5 \%)$

$31(56.4 \%)$

$170 \pm 82.9$

\begin{tabular}{|l|l|}
\hline $\begin{array}{l}10 \text { and above } \\
(\mathbf{n = 9 3 )}\end{array}$ & $\mathbf{p}$ \\
\hline $61.1 \pm 8.2$ & 0.108 \\
\hline $55(59.1 \%)$ & 0.447 \\
\hline $38(40.9 \%)$ & $<0.001$ \\
\hline $28.8 \pm 2,2$ & $<0.001$ \\
\hline $100 \pm 7.7$ & 0.495 \\
\hline $61(65.6 \%)$ & $\mathbf{0 . 0 4 0}$ \\
\hline $40(43 \%)$ & 0,333 \\
\hline $71(76.3 \%$ & 0,706 \\
\hline $35(37.6 \%)$ & 0.263 \\
\hline $61(65.6 \%)$ & 0.314 \\
\hline $31(33.3 \%)$ & $\mathbf{0 . 0 4 2}$ \\
\hline $201 \pm 92.3$ & $\mathbf{0 . 0 3 7}$ \\
\hline $195 \pm 47.9$ & 0.131 \\
\hline $39.7 \pm 6,8$ & $\mathbf{0 , 0 3 8}$ \\
\hline $115 \pm 36.9$ & $6 w-d e n$ \\
\hline
\end{tabular}

$n$ : Number

Important p-values shown as bold 
Table 5. Correlation analysis for collateral development

\begin{tabular}{|c|c|c|}
\hline & $r$ & $\mathbf{p}$ \\
\hline Age, years & 0.097 & 0.242 \\
\hline Gender & 0.146 & 0.077 \\
\hline Visceral fat & -0.415 & $<0.001$ \\
\hline BMI & -0.211 & 0,010 \\
\hline Waist circumference (cm) & -0.203 & 0.013 \\
\hline Stenosis percentage & 0.548 & $<0.001$ \\
\hline Lesion location & -0.096 & 0.244 \\
\hline Number of critical vessels & -0.136 & 0.100 \\
\hline HT, (\%) & -0.098 & 0.234 \\
\hline DM, (\%) & -0.184 & 0.025 \\
\hline CAD & -0.094 & 0.255 \\
\hline Family history, (\%) & -0.029 & 0.726 \\
\hline Smoking & -0.127 & 0.124 \\
\hline Dyslipidemia, (\%) & -0.053 & 0.522 \\
\hline Neutrophil & -0.150 & 0.070 \\
\hline Lymphocyte & -0.157 & 0.056 \\
\hline Platelet, $\left(\times 10^{3} \mu \mathrm{L}\right)$ & -0.106 & 0.200 \\
\hline Glucose, mg/dL & -0.159 & 0.053 \\
\hline CRP & -0.154 & 0.122 \\
\hline Triglycerides, mg/dL & -0.144 & 0.080 \\
\hline Cholesterol, mg/dL & -0.113 & 0.172 \\
\hline LDL, mg/dL & -0.028 & 0.735 \\
\hline
\end{tabular}

BMI: Body mass index, HT: Hypertension, DM: Diabetes mellitus, CAD: Coronary artery diseases, CRP: C-reactive protein, LDL: Low-density lipoprotein, $n$ : Number

Important p-values shown as bold

Table 6. Correlation analysis about visceral fat level

\begin{tabular}{|l|l|l|}
\hline & $\mathbf{r}$ & $\mathbf{p}$ \\
\hline Age, years & 0.143 & 0.082 \\
\hline Gender & 0.019 & 0.821 \\
\hline Collateral circulation & -0.415 & $<\mathbf{0 . 0 0 1}$ \\
\hline BMI & 0.704 & $<0.001$ \\
\hline Waist circumference, (cm) & 0.592 & $<0.001$ \\
\hline HT, (\%) & 0.106 & 0.199 \\
\hline CAD & 0.106 & 0.198 \\
\hline DM, (\%) & 0.314 & $<0.001$ \\
\hline Smoking & 0.131 & 0.111 \\
\hline Family history, (\%) & 0.060 & 0.470 \\
\hline Triglycerides, mg/dL & 0.168 & $\mathbf{0 . 0 4 1}$ \\
\hline Cholesterol, mg/dL & 0.216 & $\mathbf{0 . 0 0 8}$ \\
\hline LDL, mg/dL & 0.184 & $\mathbf{0 . 0 2 5}$ \\
\hline
\end{tabular}

BMI: Body mass index, HT: Hypertension, DM: Diabetes mellitus, CAD: Coronary artery diseases, CRP: C-reactive protein, LDL: Low-density lipoprotein Important p-values shown as bold 
weak positive correlation was determined with triglyceride $(\mathrm{r}=0.168, \mathrm{p}=0.041), \quad$ cholesterol $\quad(\mathrm{r}=0.216, \quad \mathrm{p}=0.008)$ and low-density lipoprotein $(\mathrm{r}=0.184, \mathrm{p}=0.025)$ levels. Although a very weak positive correlation was determined in the correlation analysis between other cardiac risk factors and visceral fat percentage level, these correlations were not statistically significant (Table 6).

In the multivariate logistic regression analysis performed to determine the factors affecting collateral development, visceral fat tissue and coronary stenosis percentage were determined to be statistically significant independent factors among the variables. Accordingly, it was determined that the increase in coronary stenosis percentage and the decrease in visceral fat percentage were independent predictors of good collateral artery development (Table 7).

Collateral development and visceral fat percentage, BMI, and waist circumference were compared in the ROC analysis of data. There was a statistically significant negative correlation between visceral fat level, BMI and collateral development. With $72.7 \%$ sensitivity and $58.5 \%$ specificity, a decrease was predicted in collateral

Table 7. Evaluation of the predictors of collateral development with multivariate logistic regression analysis

\begin{tabular}{|c|c|c|c|}
\hline Parameter & OR & $95 \% \mathrm{Cl}$ & $\mathbf{p}$ \\
\hline Age, years & 0.948 & $0.874-1.028$ & 0.948 \\
\hline Gender & 0.851 & $0.203-3.560$ & 0.851 \\
\hline Visceral fat & 0.740 & $0.602-0.909$ & 0.040 \\
\hline BMI, $\left(\mathrm{kg} / \mathrm{m}^{2}\right)$ & 0.989 & $0.631-1.549$ & 0.960 \\
\hline Waist circumference, $(\mathrm{cm})$ & 1.040 & $0.941-1.153$ & 0.430 \\
\hline HT, (\%) & 0.380 & $0.099-1.454$ & 0.158 \\
\hline DM, (\%) & 0.344 & $0.048-2.460$ & 0.289 \\
\hline Dyslipidemia, (\%) & 0.308 & $0.048-1.976$ & 0.214 \\
\hline Smoking, (\%) & 0.440 & $0.127-1.530$ & 0.197 \\
\hline Family history, (\%) & 3.716 & $0.798-1730$ & 0.094 \\
\hline Stenosis percentage & 1.220 & $1.070-1.390$ & 0.003 \\
\hline Lesion location & 0.409 & $0.116-1.437$ & 0.163 \\
\hline Statin, (\%) & 0.450 & $0.116-1.749$ & 0,249 \\
\hline Glucose, mg/dL & 0.994 & 0.976-1.012 & 0.494 \\
\hline Creatinine, mg/dL & 2.540 & $0.107-6020$ & 0.564 \\
\hline CRP & 0.620 & $0.336-1.114$ & 0.126 \\
\hline Triglycerides, mg/dL & 0.993 & $0.975-1.011$ & 0.450 \\
\hline Cholesterol, mg/dL & 1.016 & 0.937-1.101 & 0.699 \\
\hline
\end{tabular}

Table 8. ROC analysis

\begin{tabular}{|c|c|c|c|c|c|c|}
\hline & AUC & $95 \% \mathrm{Cl}$ & Cut-off & Sensitivity & Specificity & $\mathbf{p}$ \\
\hline Visceral fat & 720 & $638-801$ & 125 & $72.7 \%$ & $58.5 \%$ & $<0.001$ \\
\hline BMI, $\left(\mathrm{kg} / \mathrm{m}^{2}\right)$ & 600 & $508-692$ & 28.3 & $72.7 \%$ & $51.2 \%$ & 0.370 \\
\hline Waist circumference, (cm) & 587 & $495-679$ & 101.5 & $66.7 \%$ & $47.6 \%$ & 0.690 \\
\hline
\end{tabular}

ROC: Receiver operating characteristic curve, BMI: Body mass index, AUC: Area under the curve, Cl: Confidence interval Important $p$-values shown as bold 


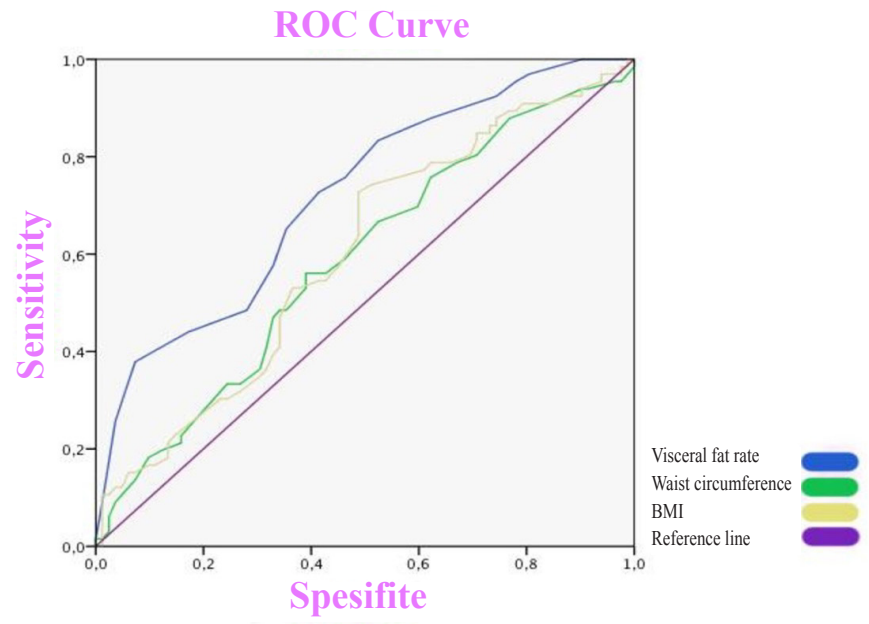

Figure 2. ROC analysis, comparison of the relation between collateral development and visceral fat percentage, BMI (body mass index), waist circumference with ROC analysis

ROC: Receiver operating characteristic

development at 12.5 cut-off level for visceral fat percentage (Table 8, Figure 2).

\section{Discussion}

It is considered that the development of coronary collateral vessels in human heart is processed through the combined development of two different types of adaptation mechanisms, angiogenesis and arteriogenesis ${ }^{(10)}$. Endothelial functions are known to have a crucial role in the maturation process of collateral vessels ${ }^{(11,12)}$. The interpersonal difference in collateral development level is suggested to be caused by endothelial dysfunction. Fat tissues do not only store fatty acids, they also play a central role in glucose and lipid metabolism. Numerous hormones such as tumor necrosis factor alpha (TNF- $\alpha$ ), interleukin-6 (IL-6), adiponectin and leptin are produced in adipose tissue and increase in adipose tissue mass directly increases systemic inflammation ${ }^{(13)}$. In the current study population, visceral fat percentage was significantly higher in the poor collateral group compared to the good collateral group $(\mathrm{p}=0.011)$. A significant negative relation was determined between visceral fat percentage and Rentrop flow upon separating the patients into sub-groups according to the Rentrop classification $(\mathrm{p}=0.003)$. High visceral fat percentage was determined to be a negative predictor for coronary collateral development in logistic regression analysis. In our study, we showed that the increase in visceral fat percentage was an independent factor in terms of poor collateral development. Regarding other cardiovascular risk factors, apart from visceral fat tissue, there is no significant difference between the subjects with good and poor collateral development.

Among cardiovascular risk factors, diabetes, HT, hyperlipidemia, smoking and family history of CAD were observed to be more common in the group with high visceral fat percentage; however, no statistically significant difference was determined in the risk factors other than diabetes. The frequency of other factors was more prominent in the group with high visceral fat percentage, albeit not statistically significant.

The measurement of waist circumference reveals abdominal obesity ${ }^{(14)}$. However, it does not distinguish visceral fat from subcutaneous fat tissue. The reason for that is visceral fat tissue is not affected from skin and muscle layers as in waist circumference measurement. We determined higher waist circumference and BMI in people with high visceral fat percentage $(\mathrm{p}<0.001)$. Although a positive correlation was determined between visceral fat percentage with waist circumference and BMI, visceral fat percentage was determined to be a determinant on collateral development with higher sensitivity and specificity compared to other factors. Although a statistically significant negative correlation was determined between collateral development and visceral fat percentage and BMI, no statistically significant difference was determined between those and waist circumference despite a negative correlation. Accordingly, it was determined that the effect of visceral fat tissue on coronary collateral development was stronger compared to BMI and waist circumference.

There is a positive correlation between body mass and peripheral leukocyte count. It was shown in a high number of studies that inflammatory proteins in circulation (CRP, IL-6, PAI-1, P-selectin, vascular cell adhesion molecule-1, 
fibrinogen, angiotensinogen, SAA3) are increased with an increase in body mass ${ }^{(15)}$.

Coronary collaterals are potential vascular structures presenting in normal heart and emerge in the presence of serious CAD and work for the protection of myocardial vitality. It is well-known that the presence of collateral vessels and increased collateral circulation level are associated with left ventricular function status ${ }^{(16,17)}$. Studies have demonstrated that collateral circulation reduces myocardial ischemia, decreases infarct area, positively increases left ventricular function, decreases ventricular aneurysm formation, and most importantly, increases survival ${ }^{(18,19)}$. However, left ventricular systolic functions were statistically similar between the groups of good and poor collateral development in our analysis. This difference may be determined more accurately in studies of patient follow-up after discharge.

While collateral vessel development is formed as a response to severe coronary stenosis, the factors that affect collateral development level in the presence of severe CAD may not be clearly determined ${ }^{(20)}$. Stenosis in the artery providing the collateral flow (donor artery) is another important factor in collateral vessel development. It has been indicated that stenosis rate should be $\geq 90 \%$ and collateral vessel diameter should be above $100 \mu \mathrm{m}$ for angiographic imaging ${ }^{(21)}$. Arteriogenesis is induced in the result of increased "shear stress" after serious artery obstructions $^{(22)}$. It is suggested that MCP-1 (monocyte chemotactic protein-1) is effective on this mechanism ${ }^{(10)}$. While there is maximum shear at the beginning, this is gradually reduced with the increasing diameter of collateral vessels ${ }^{(23)}$. Assuming that hypertension will play a facilitating role in this mechanism, it can be considered to affect collateral development positively. In the result of some studies investigating the relationship between the presence of coronary collateral in hypertension and left ventricular hypertrophy in CAD, it has been determined that hypertensive patients have better developed collateral, and a positive relationship has been demonstrated between coronary collaterals and left ventricular wall thickness ${ }^{(24,25)}$. Although studies on humans and animals have shown that epicardial coronary arteries are dilated in hypertrophic ventricle, it is now clear why left ventricular hypertrophy increases CCC; it may be associated with myocardial ischemia. While the hypertension incidence was higher in the poor collateral group compared to the good collateral group in our study, no significant difference was determined between the two groups. We have attributed this result to the fact that HT was under control due to drug therapy in our patients.

In type II DM, in which insulin resistance plays a significant role, deaths are largely associated with cardiovascular diseases ${ }^{(26)}$. There are various opinions on the effect of DM on collateral development. Abaci et al. ${ }^{(27)}$ have shown that collateral development is weaker in DM due to the fact that endothelial function, which plays a large role in collateral development, is impaired in diabetics. Melidonis et al. ${ }^{(28)}$ have determined higher coronary collateral vessel development rate in diabetics compared to the non-diabetics. Zbinden et al. ${ }^{(29)}$ did not determine a significant difference between the two groups with regard to collateral flow in their study in which they compared patients with or without DM. As in diabetic retinopathy, DM is known to induce angiogenesis but inhibits arteriogenesis ${ }^{(30)}$. In our study, 51 of 148 patients had diabetes, and DM prevalence was not determined to be statistically significant even though it was higher in the poor collateral group, which might be due to low diabetic case number.

\section{Study Limitations}

Although no collateral was observed with angiographic method, the recovery in left ventricular function with revascularization is attributed to the fact that capillary collateral flow that could not be imaged in angiography protects myocardial function in a hibernated manner ${ }^{(10)}$. Considering that we can detect collaterals above $100 \mu \mathrm{m}$, the presence of collateral flow at an angiographically 
invisible level may have prevented the development of infarction in some cases with poor collaterals. The use of angiography in the evaluation of collateral flow and this limitation in the collateral evaluation of angiography may have affected the results.

\section{Conclusion}

Despite the advancements in treatment modalities, cardiovascular diseases are still the first underlying reason of morbidity and mortality around the world. This study reveals that one of the components of obesity, increased visceral fat percentage, may negatively affect coronary collateral development in metabolic syndrome. In addition, cardiovascular diseases are increased in parallel with the increase in visceral fat tissue. The cardiovascular risk factors and the development of cardiovascular diseases may be prevented with visceral fat percentage followup and treatment. For this reason, ensuring weight loss, regular exercise and healthy diet poses utmost importance in these patients.

\section{Ethics}

Ethics Committee Approval: Ethics committee approval of our study was obtained from Dicle University Faculty of Medicine Clinical Research Ethics Committee on 25.12.2015 with the decision number 139 .

Informed Consent: The study was designed retrospectively. All patients have been informed preceding the study.

Peer-review: Externally peer-reviewed.

\section{Authorship Contributions}

Surgical and Medical Practices: A.A., Bu.A, Concept: M.Ö., M.D., Design: R.K., B.A., Data Collection or Processing: A.A., Analysis or Interpretation: A.A., T.G., Literature Search: A.A., Bu.A., Writing: A.A., T.G.

Conflict of Interest: The authors declared that there was no conflict of interest related to this article.

Financial Disclosure: The authors declared that this study received no financial support

\section{References}

1. Ross R. Atherosclerosis--an inflammatory disease. N Engl J Med 1999;340:115-26.

2. Cohen MV. The functional value of coronary collaterals in myocardial ischemia and therapeutic approach to enhance collateral flow. Am Heart J 1978;95:396-404.

3. Charney R, Cohen M. The role of the coronary collateral circulation in limiting myocardial ischemia and infarct size. Am Heart J 1993;126:93745 .

4. Newman PE. The coronary collateral circulation: determinants and functional significance in ischemic heart disease. Am Heart J 1981;102:43145

5. Schwarz F, Flameng W, Ensslen R, Sesto M, Thormann J. Effect of coronary collaterals on left ventricular function at rest and during stress. Am Heart J 1978;95:570-7.

6. Vanoverschelde JL, Wijns W, Depré C, et al. Mechanisms of chronic regional postischemic dysfunction in humans. New insights from the study of noninfarcted collateral-dependent myocardium. Circulation $1993 ; 87: 1513-23$

7. Murphy JG, Lloyd MA. Mayo Clinic Cardiology Concise Textbook.3rd Ed. Rochester, Minnesota: Mayo Clinic Scientific press, 2005;p.687-781.

8. de Vries J, Anthonio RL, van den Heuvel AF, et al. Incidence and angiographic predictors of collateral function in patients with stable coronary artery disease scheduled for percutaneous coronary intervention. Catheter Cardiovasc Interv 2007;70:197-202.

9. Rahmouni K, Mark AL, Haynes WG, Sigmund CD. Adipose depot-specific modulation of angiotensinogen gene expression in diet-induced obesity. Am J Physiol Endocrinol Metab 2004;286:891-5.

10. van Royen N, Piek JJ, Buschmann I, Hoefer I, Voskuil M, Schaper W. Stimulation of arteriogenesis; a new concept for the treatment of arterial occlusive disease. Cardiovasc Res 2001;49:543-53.

11. Glasser SP, Selwyn AP, Ganz P. Atherosclerosis: risk factors and the vascular endothelium. Am Heart J 1996;131:379-84.

12. Schaper W, Sharma HS, Quinkler W, Markert T, Wünsch M, Schaper J. Molecular biologic concepts of coronary anastomoses. J Am Coll Cardiol 1990;15:513-8.

13. Engeli S, Gorzelniak K, Kreutz R, Runkel N, Distler A, Sharma AM. Coexpression of renin-angiotensin system genes in human adipose tissue. $\mathrm{J}$ Hypertens 1999;17:555-60.

14. Pouliot MC, Despre's JP, Lemieux S, et al. Waist circumference and abdominal sagittal diameter: best simple anthropometric indexes of abdominal visceral adipose tissue accumulation and related cardiovascular risk in men and women. Am J Cardiol 1994;73:460-8.

15. Ling Y, Lee H, Berg AH, Lisanti MP, Shapiro L, Scherer PE. The Lipopolysaccharide-activated Toll-like Receptor (TLR)-4 Induces Synthesis of the Closely Related Receptor TLR-2 in Adipocytes JBC 2000;275:24255-63.

16. Blanke H, Cohen M, Karsch KR, Fagerstrom R, Rentrop KP. Prevalence and significance of residual flow to the infarct zone during the acute phase of myocardial infarction. J Am Coll Cardiol 1985;5:827-31. 
17. Nicolau JC, Pinto MA, Nogueira PR, Lorga AM, Jacob JL, Garzon SA. The role of antegrade and collateral flow in relation to left ventricular function post-thrombolysis. Int J Cardiol 1997;61:47-54.

18. Habib GB, Heibig J, Forman SA, et al. Influence of coronary collateral vessels on myocardial infarct size in humans. Results of phase I thrombolysis in myocardial infarction (TIMI) trial. The TIMI Investigators. Circulation 1991;83:739-46.

19. Hirai T, Fujita M, Nakajima H, et al. Importance of collateral circulation for prevention of left ventricular aneurysm formation in acute myocardial infarction. Circulation 1989;79:791-6.

20. Lazarous DF, Scheinowitz M, Shou M, et al. Effects of chronic systemic administration of basic fibroblast growth factor on collateral development in the canine heart. Circulation 1995;91:145-53.

21. Newman PE. The coronary collateral circulation: determinants and functional significance in ischemic heart disease. Am Heart J 1981;102:43145 .

22. Scholz D, Schaper W. Preconditioning of arteriogenesis. Cardiovasc Res 2005;65:513-23.

23. Heil M, Schaper W. Pathophysiology of collateral development. Coron Artery Dis 2004;15:373-8.
24. Braunwald E. Heart Disease: A Textbook of Cardiovasculer Medicine. Philadelphia: W.B. Saunders Company 1997.

25. Zenon SK, Dimitrios TK, Nicholas AM, Evangelos PM, Thomas D, Pavlos KT. Coronary collateral circulation in coronary artery disease and systemic hypertension. Am J Cardiol 1991;67:687-90.

26. Gray RP \& Yudkin JS Int Textbook of Diabetes mellitus, 1997.

27. Abaci A, Oğuzhan A, Kahraman S, et al. Effect of diabetes mellitus on formation of coronary collateral vessels. Circulation 1999;99:2239-42.

28. Melidonis A, Tournis S, Kouvaras G, et al. Comparison of coronary collateral circulation in diabetic and nondiabetic patients suffering from coronary artery disease. Clin Cardiol 1999;22:465-71.

29. Zbinden R, Zbinden S, Billinger M, Windecker S, Meier B, Seiler C. Influence of diabetes mellitus on coronary collateral flow: an answer to an old controversy. Heart 2005;91:1289-93.

30. Schaper W, Buschmann I. Collateral circulation and diabetes. Circulation 1999;99:2224-6. 